\title{
Gender or Proactivity? The Instance of Information Systems Students' Occupational Self-Efficacy
}

\author{
Sarit Rashkovits ${ }^{1} \&$ Rami Rashkovits ${ }^{2}$ \\ ${ }^{1}$ Department of Health Systems Management, The Max Stern Yezreel Valley College (YVC), Yezreel Valley, Israel \\ ${ }^{2}$ Department of Management Information Systems, The Max Stern Yezreel Valley College (YVC), Yezreel Valley, \\ Israel \\ Correspondence: Sarit Rashkovits, Department of Health Systems Management, The Max Stern Yezreel Valley \\ College (YVC), Yezreel Valley, 19300 Israel. Tel: 972-4-642-3504.
}

Received: August 13, 2016

doi:10.5430/irhe.v1n2p227
Accepted: September 8, 2016

Online Published: September 17, 2016

URL: http://dx.doi.org/10.5430/irhe.v1n2p227

\begin{abstract}
Purpose- Due to persisting gender inequality in the transition from university to the labour market in Science, Technology, Engineering and Mathematics (STEM) occupations, the purpose of this research was to investigate empirically the joint effect of gender and proactivity on Information Systems (IS) students' occupational self-efficacy (OSE), as well as the mediating role of proactivity in the gender-occupational self- efficacy link.

Design/methodology/approach- Two cross-sectional quantitative studies: the first with a sample of 113 IS students and the second employing a longitudinal design with 52 IS students.

Findings- The results indicate that gender had no effect on IS students' OSE beyond proactivity. However, gender had an indirect effect on their OSE mediated by proactivity.

Research limitations/implications- The analyses included several control variables (income, age, academic achievement, and conscientiousness). However, future research may include larger samples that allow controlling additional variables such as cultural differences.

Practical implications- Since the findings indicate that OSE of less proactive students is lower, it is especially vital to focus effort on enhancing these students' OSE during their academic studies.

Social implications- Cultivating females' proactivity may assist in decreasing the existing gender inequality in the transition from university to the labour market in STEM occupations, as well as promoting women's success in other exceptional challenges in the workplace.

Originality/value- Students' OSE has not received much research attention, in spite of the importance of the transition from university to the labour market. This research initially addresses this gap. Moreover, it highlights the mediating role of proactivity in the gender-OSE link among IS students.
\end{abstract}

Keywords: occupational self-efficacy, proactivity, gender

\section{Introduction}

Careers in information systems (IS) enjoy high status and salaries (Bureau of Labor Statistics, 2013); therefore, the entrance of women into this occupation is important for reducing gender inequality in socio-economic status. However, reports from many western developed nations reveal that the IS field is still male-dominant (Nielson \& Von Hellens, 2006), and that the percentage of women enrolling to IS programs is dropping (NCWIT, 2010). Therefore, it is important to enhance the knowledge regarding the different mechanisms that play a role in women's entrance and persistence in this field.

Researchers have demonstrated the importance of seemingly voluntary individual decisions in much of the persisting gender gaps in male-dominant occupations (e.g. Correll, 2001, 2004). Social cognitive theory considers behaviour not as the by-product of the person- environment interaction, but rather as a co-determinant of this interaction (Bandura, 1986). The most central and pervasive mechanism in social cognitive theory is the self- efficacy beliefs. Self-efficacy is defined as "people judgment of their capabilities to organise and execute courses of action required to attain designated types of performances" (Bandura, 1986). An individual judgment of self-efficacy influences the 
initiation, intensity, and persistence of behaviour and thus affects the relevant performance or achievements (Bandura, 2000). Self-efficacy has been introduced into the career literature by Hackett and Betz (1981), who specifically considered women's self-efficacy regarding different career-related behaviours. Self- efficacy has been applied to major aspects of career development such as career choice, and performance and persistence in educational and occupational pursuits (Lenet \& Brown. 1994). However, in the present study we specifically concentrate on occupational self-efficacy (OSE), which is referring to the competence that a person feels concerning the ability to fulfil the tasks involved in her or his job successfully (Schyns \& von Collani, 2002; Rigotti et al., 2008). In tandem with social cognitive theory (e.g. Bandura, 2011), previous research has shown that levels of occupational self-efficacy predict job performance, job satisfaction and commitment, and objective and subjective career success (Mohr 2008; Rigotti et al., 2008; Abele \& Spurk, 2009; Spurk \& Abele, 2014).

Even though much effort and persistence are needed on graduation for pursuing professional careers (Brown et. al., 2006), surprisingly, no previous research has been devoted to students' OSE. Additionally, a recent survey indicates that the link between the field of study at university level and occupation is stronger for men than for women, since when women pursue STEM studies they are less likely to end up working in this field (OECD Council Report, 2012), meaning that females' OSE and the resukting persistence are with special importance in male dominant fields. Therefore, our first aim is to study whether female IS students reveal lower levels of OSE than male students.

However, OSE might as well be affected by individual differences rather than by gender. Proactivity, the individual variability in agency, is defined as a "relatively stable tendency to affect environmental change", in contrast to a passive tendency to be reactively shaped by environments (Bateman \& Crant, 1993; Crant \& Bateman, 2000). Individuals with a proactive personality are relatively unconstrained by situational forces. They identify opportunities, act on them, show initiative, and persevere until they bring about meaningful changes rather than passively adapt the circumstances (Bateman \& Crant, 1993). Therefore, proactivity may have special importance for the generation of self-efficacy regarding high status and competitive occupational domains such as IS. Accordingly, we further aim to test the effect of proactivity on OSE. Overall, we aim to investigate the joint effect of gender and proactivity on OSE in IS (see Figure 1).

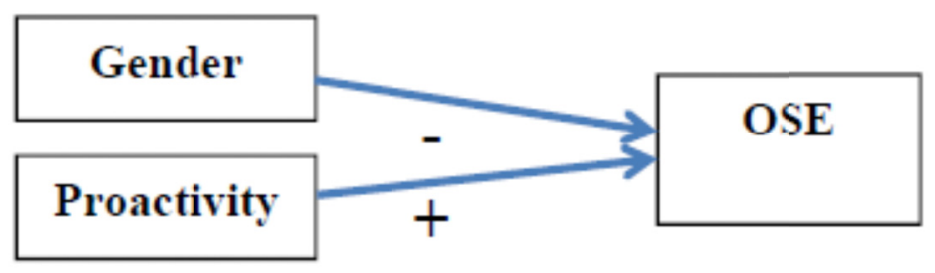

Figure 1. Conceptual Model- study 1

\section{Study 1}

\subsection{Gender and IS Students' OSE}

The concept of self-efficacy has been defined in three different ways: as a relatively more global construct generalised over several domains (e.g. Shelton, 1990); as a domain-specific variable (e.g. Schwaezer \& Funch, 1995); and as a task-specific variable to predict circumscribed behaviour, for example, to solve an algebra problem (e.g. Pajares, 1996). OSE is a medium-level generality construct related to the occupational domain, so that it permits an investigation of individual differences in self-efficacy associated with various professions (Schyn \& von Collani, 2002).

Social cognitive theory describes four main sources of self-efficacy including enactive mastery experience, vicarious experience, verbal persuasion, and physiological and affective states. These sources were previously connected to gender inequality in self efficacy (Hackett \& Betz, 1981). Male and female IS students are exposed to the same enactive mastery experience, meaning the academic activity of attending lectures, performing assignments and taking examinations; therefore vicarious experience might seem as less relevant to gender inequality in the OSE of students. Nonetheless, previous research has found that women assess their ability as lower than men in tasks that were described as "male," even when achieving the same scores (Correll, 2004). Moreover, during their studies, IS students are still exposed to role models and to verbal persuasion. In more detail, vicarious experience refers to 
seeing a 'similar other' successfully perform the behaviour and appraise one's own performance against the performance of that similar other. Since a male dominant occupational field means that female models are relatively rare, it is expected that females have lower chances to develop high self-efficacy for this field in compared to males (Clark Blickenstaff, 2005). Secondly, verbal persuasion refers to the expression of faith in the individual's capabilities in the relevant domain by others, and was previously found to affect students' career self-efficacy (Luzzo \& Taylor, 1994). When an occupation is male-dominant it is most likely that it represent the prevalent society's attitudes regarding its fitness for males versus females. Therefore, again, it is most likely that females encounter less verbal persuasion regarding their fitness for this occupation relative to males (Clark Blickenstaff, 2005). Thus females are less likely to develop high self-efficacy in this occupational domain than males.

Therefore we hypothesise:

Hypothesis 1: Female IS students will experience lower levels of OSE than male IS students.

\subsection{Proactivity and OSE}

Scholars have referred to proactivity as individual variability in agency, and have defined proactive personality as a "relatively stable tendency to affect environmental change", in contrast to a passive tendency to be reactively shaped by the environment (Bateman \& Crant, 1993; Crant \& Bateman, 2000). Moreover, as was phrased by Brown et. al, (2006): "researchers generally agree that distal personality constructs impact relevant work behaviours through proximal motivational constructs, such as self-efficacy (Kanfer, 1992). In line with this thinking, Frese and Fay (2001) have argued that the impact of proactive personality on behaviour and outcomes is mediated through domain-specific orientations, such as self-efficacy. In effect, Frese and Fay suggested that general dispositional tendencies to feel a sense of agency across situations spill over into specific domains, colouring an individual's self-efficacy judgments." (Brown et. al, 2006). In support with this view, research has also demonstrated the mediating role of self efficacy in the effect of proactivity in several domains (e.g. Li, Liu, Liu, \& Wang, 2016; Lishan, Xinhua, \& Peifang, 2013; Prabhu, McGuire, Drost, \& 2012).

Recent meta-analyses (Fuller, \& Marler, 2009; Thomas et al., 2010) confirmed the relation of proactive personality with objective and subjective career success. Moreover, proactivity was found to be positively related to such desirable and challenging work-related manifests as transformational leadership (Bateman \& Crant, 1993; Crant \& Bateman, 2000) and the challenge of a job search on graduation (Brown et al., 2006). Proactive people feel relatively unconstrained by situational forces, e.g. pathfinders, who take it upon themselves to have an impact on the situation they face. Therefore they are more liable to believe in their ability to achieve highly in challenging situations, such as competitive careers and work situations. Taking into account that the IS occupational field is prestigious and competitive, we suggest that more proactive IS students will experience higher OSE in this field.

Therefore we hypothesise:

Hypothesis 2: There will be a positive relation between proactivity and OSE, so IS students with higher proactivity will score higher on OSE.

\section{Method}

\subsection{Sample}

113 students, studying in the same information systems department in an academic institution (43 students in the first year, 41 in the second year, and 28 in the third year) participated in the study. Their average age was 25.59 years (s.d. $=3.26$ ); $78 \%$ were born in Israel; and $63 \%$ were males.

\subsection{Procedure}

Towards the end of the first term of the academic year, the participants were invited to fill in the research questionnaire by a research assistant at the end of the lectures after receiving a short explanation. The participation was voluntary and anonymity was guaranteed. About $75 \%$ of all the students in this IS department showed up to the classes that the research assistant attended, and the participation rate was about $95 \%$. The research questionnaire included research variables (i.e. gender, academic achievements, proactivity, and OSE) as well as several demographic, personal and personality control variables (i.e. income, age, and conscientiousness).

\subsection{Research Variables and Measures}

Gender. The participants were asked to report it in the research questionnaire.

Proactivity. This measure consisted of 10 items using a Likert-type scale (from $1=$ very strongly disagree to $7=$ very strongly agree) developed by Bateman and Crant (1993). Participants indicated their agreement on a 7-point scale 
(strongly disagree $=1$ to strongly agree $=7$ ). An example item: "If I believe in an idea, no obstacle will prevent me from making it happen".

The Cronbach's Alpha reliability (as reported in Table 1) was 0.89 .

Occupational self-efficacy (OSE). This measure consisted of five items using Likert's type scale (from 1 = very strongly disagree to 7 = very strongly agree) based on Rigotti et. al. (2008). An example item: "I can remain calm facing difficulties in my future job because I can rely on my occupational abilities".

The Cronbach's Alpha reliability in the first sample (as reported in Table 1) was 0.75 .

Control Variables. We controlled demographic variables of the students' age (in years) and income level (the combined income of both parents per month). The income level was rated on a scale of six degrees as follows: 1beneath 4,000 NIS (New Israeli Shekels); 2- between 4,000-7,000 NIS; 3- between 7,000-10,000 NIS; 4- between 10,000-20,000 NIS; 5-between 20,000-30,000 NIS; 6- above 30,000 NIS.

We further controlled for conscientiousness: a personality characteristic that implies the degree of organisation, persistence, and motivation in goal-directed behaviour (John \& Srivastava, 1999). We chose to control this factor since it was previously found as most related to job performance and success among all five personality factors (Hurtz \& Donovan, 2000). Furthermore, conscientiousness was also found to be somewhat related to proactivity in that both are goal-oriented and imply persistence towards having closure on an objective (Bateman \& Crant, 1993).

This measure consisted of five items using a Likert-type scale (from $1=$ very strongly disagree to $7=$ very strongly agree) developed by John \& Srivastava (1999). An example item: "I see myself as someone who does a thorough job".

The Cronbach's Alpha reliability (as reported in Table 1) was 0.85 .

Finally, we controlled the students' academic achievements, since enactive mastery experience is known to affect self-efficacy (Babdura, 2002). We referred to the mean score of the students' grades over the previous terms that they reported in the research questionnaire. First-year students were asked to refer to their average score on their assignments during the term.

\section{Results}

\subsection{Descriptive Statistics}

As seen in Table 1, the students' OSE had a significant negative correlation with gender $(r=0.22, p<0.05)$, meaning that female IS students had lower OSE. OSE also had a significant positive correlation with proactivity ( $\mathrm{r}=0.54$. $\mathrm{p}<0.01)$, as well as with conscientiousness $(\mathrm{r}=0.43, \mathrm{p}<0.01)$, and with academic achievements $(\mathrm{r}=0.33, \mathrm{p}<0.01)$.

Table 1. Research variables, means, standard deviations and inter-correlations (Sample 1)

\begin{tabular}{|c|c|c|c|c|c|c|c|c|c|}
\hline & Mean & S. D. & 1 & 2 & 3 & 4 & 5 & 6 & 7 \\
\hline 1 OSE in IS & 4.56 & 0.94 & 0.75 & & & & & & \\
\hline 2 Gender & & & $-0.22 *$ & 1 & & & & & \\
\hline 3 Academic achievements & 83.90 & 8.06 & $0.33 * *$ & 0.05 & 1 & & & & \\
\hline 4 Proactivity & 4.91 & 0.86 & $0.54 * *$ & -0.18 & 0.09 & 0.89 & & & \\
\hline 5 Age (in years) & 25.59 & 3.26 & 0.04 & $-0.33 * *$ & $-0.30 * *$ & -.002 & 1 & & \\
\hline $\begin{array}{ll}6 & \text { Income level }\end{array}$ & 3.86 & 1.44 & -0.02 & 0.01 & 0.02 & -0.09 & -0.10 & 1 & \\
\hline 7 Conscientiousness & 5.70 & 0.85 & $0.43 * *$ & -0.004 & $0.26^{*}$ & $0.55^{* *}$ & 0.001 & -0.11 & 0.85 \\
\hline
\end{tabular}

**. Correlation is significant at the 0.01 level (2-tailed). *. Correlation is significant at the 0.05 level (2-tailed).

Proactivity had a significant positive correlation with conscientiousness $(\mathrm{r}=0.54 . \mathrm{p}<0.01)$. Also, age had a significant negative correlation with gender $(\mathrm{r}=-0.33, \mathrm{p}<0.01)$, and with academic achievements $(\mathrm{r}=0.030, \mathrm{p}<0.01)$, meaning that females were younger, and that older students achieved lower academic achievements. 


\subsection{Hypotheses Testing}

For testing our research hypotheses, we used multiple regression analyses with age, income level, conscientiousness, and academic achievements as control variables.

As seen in Table 2, model 1, in contrast to Hypothesis 1, gender did not have a significant effect on the IS students' OSE beyond the effect of proactivity.

Table 2. Multiple regression analyses (Sample 1)

\begin{tabular}{lcccccc}
\hline & \multicolumn{3}{c}{$\begin{array}{c}\text { Model 1: JSE in IS } \\
R^{2}=0.48\end{array}$} & \multicolumn{3}{c}{ Model 2: Proactivity } \\
$R^{2}=0.40$
\end{tabular}

However, in agreement with Hypothesis 2, proactivity had a significant effect on the students' OSE beyond the effect of gender $(\mathrm{p}<.001)$.

Nevertheless, as can be seen in Table 2, Model 2, we unpredictably found that female students were significantly lower on proactivity than males $(\mathrm{p}<0.05)$. Therefore, we used a mediation analyses (Hayes, 2013; See Figure 2) for testing the indirect effect of gender on OSE via the mediating variable of proactivity. Hayes's (2013) approach is based on conditional bootstrapping of the mediation effect. This procedure is an extension of the Sobel test (Sobel, 1982) and is recommended over that of Baron and Kenny (1986), because it does not assume a normal sampling distribution of indirect effects. The hypothesis was tested by SPSS PROCESS- a computational tool for path analysis-based mediation and moderation analyses (Hayes, 2013). This mediation analysis includes three steps: the first is regression analysis testing of the effect of gender (the independent variable) on proactivity (the mediating variable; see Table 2, model 2). The second step is a regression analysis identical to the regression we used to test Hypothesis 1, and 2 (see Table 2, model 1) in which the independent variable (gender) and the mediating variable (proactivity) regressed on the dependent variable (OSE). In the final step, the indirect effect is tested. We found that gender had a significant negative indirect effect on OSE mediated by proactivity (ab=-0.23, CI 95\% [-0.48, -0.06$]$ ). We included the explanatory variable of academic achievements, age, income level and conscientiousness in all three steps.

\section{Study 2}

Since in the first study the students' proactivity and OSE were measured at the same time, the second study aims to confirm the mediating role of proactivity in the indirect effect of gender on OSE using a longitudinal design, meaning that the dependent variable of OSE will be measured several months after the mediating variable of proactivity (see Figure 2). This design is recommended for limiting common method bias (Podsakoff \& Podsakoff, 2003).

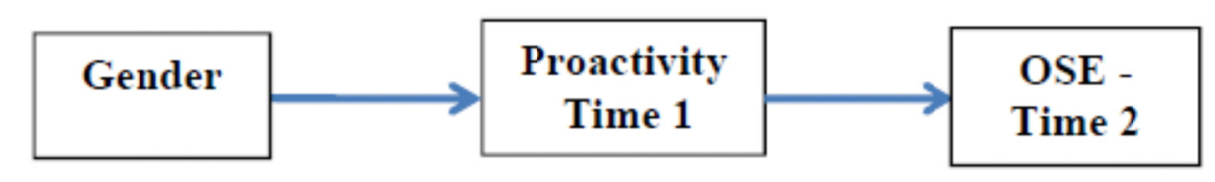

Figure 2. Conceptual Model- study 2

Our finding that the female students scored significantly lower on proactivity than the male students pertains to the question of whether proactivity is a "gender-free" trait or whether it is "male biased". An influential approach to the conceptualisation of gender stereotypes and gender self-concepts is the distinction between more "masculine" traits that are agentic- instrumental traits (e.g. active, decisive) and more "feminine" traits that are communal- expressive 
(e.g. caring, emotional). However, research has found that the relationship between biological sex and agentic and communal traits is complex (Abele, 2003). However, it was previously found that proactivity is positively correlated with such "manlike" features as the need for achievement and dominance (Bateman \& Crant, 1993). Nevertheless, to the best of our knowledge, there has been no previous research aimed at investigating gender differences in proactivity. However, in a large-scale study conducted with a sample of 496 employees from a variety of occupations and organisations, a significant negative correlation was found between gender and proactivity as was rated by both, self, and significant others (Seibert et al., 1999), meaning that females demonstrated a lower proactivity level than males. In sum, our finding regarding the gender-proactivity link has some theoretical and previous empirical support.

Taking the gender-proactivity link together with the relationship between proactivity and IS students' OSE, we suggest that gender will have an indirect effect on IS students' OSE mediated by proactivity.

Thus we hypothesise:

Hypothesis 3: There will be a negative relation between gender and proactivity so the female students' proactivity will be lower than that of the male students.

Hypothesis 4: There will be a positive relationship between proactivity and OSE (Time 2).

Hypothesis 5: There will be a negative indirect effect of gender on IS students' OSE (Time 2) mediated by proactivity, so female students will have lower OSE than the male students.

\section{Method}

\subsection{Procedure and Sample}

At the end of the second term, meaning 6 months after the previous administration, the participants were invited to fill in the research questionnaire again by the same research assistant and in the same way (i.e. at the end of the lectures). The participation was voluntary and anonymity was guaranteed. About $75 \%$ of all the students in this IS department attended the classes and their participation rate was about $80 \%$. The sample included the 52 IS students who filled in the research questionnaire both times (24 students in the first year, 20 in the second year, and 7 in the third year). The average age was 24.5 years (s.d. $=1.770$ ); $75 \%$ were born in Israel; and 54\% were males.

\subsection{Research Variables and Measures}

Explanatory variables, gender and proactivity, were measured at time 1, as described above in study 1.

Dependent variable: OSE was measured at time 2 using the same scale described above in study 1 . The Cronbach's Alpha reliability, as reported in Table 3, was 0.77.

Control variables: age, income level, and conscientiousness were measured at time 1, as described above in study 1. Academic achievements were measured again at time 2 in the same way as described above.

\section{Results}

\subsection{Descriptive Statistic}

As seen in Table 3, OSE in IS had a significant positive correlation with proactivity $(r=0.41 . p<0.01)$ meaning that proactive students score higher on OSE in IS.

Also, conscientiousness had a significant positive correlation with proactivity $(\mathrm{r}=0.49 . \mathrm{p}<0.01)$, and with academic achievements $(r=0.31, p<0.05)$. Finally, age had a significant negative correlation with gender $(r=-0.35, p<0.05)$, meaning that the females were younger.

Table 3. Research variables, means, standard deviations and inter-correlations (Sample 2)

\begin{tabular}{|c|c|c|c|c|c|c|c|c|c|c|}
\hline & & Mean & S. D. & 1 & 2 & 3 & 4 & 5 & 6 & 7 \\
\hline 1 & OSE in IS- Time 2 & 4.58 & .95 & .77 & & & & & & \\
\hline 2 & Gender & & & -.09 & 1 & & & & & \\
\hline 3 & $\begin{array}{l}\text { Academic achievements- } \\
\text { Time } 2\end{array}$ & 79.43 & 7.57 & .18 & -.02 & 1 & & & & \\
\hline 4 & Proactivity & 4.98 & .87 & $.41 * *$ & -.22 & .03 & .89 & & & \\
\hline 5 & Age (in years) & 24.51 & 1.79 & .01 & $-.35^{*}$ & -.11 & .02 & 1 & & \\
\hline 6 & Income level & 3.9 & 1.43 & -.04 & -.1 & .07 & -.11 & .26 & 1 & \\
\hline 7 & Conscientiousness & 5.76 & .82 & .27 & -.004 & $.31 *$ & $.49 * *$ & -.03 & -.02 & .87 \\
\hline
\end{tabular}

Correlation is significant at the 0.01 level (2-tailed). *. Correlation is significant at the 0.05 level (2-tailed). 


\subsection{Hypothesis Testing}

For testing the indirect effect of gender on OSE (in Time 2) via the mediating variable of proactivity, we used Hayes' (2013) approach with SPSS PROCESS (as detailed above in study 1). In the first step in agreement with Hypothesis 3 (see Table 3, Model 2), we found a significant negative effect of gender (the independent variable) on proactivity (the mediating variable) $(\mathrm{p}<0.05)$.

Table 4. Multiple regression analyses (Sample 2)

\begin{tabular}{lcccccc}
\hline & \multicolumn{2}{c}{ Model 1: OSE in IS- Time 2 } & \multicolumn{3}{c}{ Model 2: Proactivity } \\
$R^{2}=0.48$ & & \multicolumn{2}{c}{ - } & \\
\hline & $\mathrm{B}$ & Std. Error & Sig. & $\mathrm{B}$ & Std. Error & Sig. \\
\hline Gender & 0.24 & 0.30 & 0.44 & -0.54 & 0.26 & 0.045 \\
\hline Proactivity & 0.38 & 0.18 & 0.049 & & & \\
\hline $\begin{array}{l}\text { Academic achievements - } \\
\text { Time 2 }\end{array}$ & 0.02 & 0.02 & 0.35 & -0.05 & 0.08 & 0.51 \\
\hline Age(in years) & 0.04 & 0.09 & 0.68 & -0.06 & 0.08 & 0.60 \\
\hline Income level & -0.02 & 0.09 & 0.83 & -0.05 & 0.03 & 0.56 \\
\hline Conscientiousness & 0.13 & 0.20 & 0.51 & 0.58 & 0.15 & 0.000 \\
\hline
\end{tabular}

In the second step in agreement with Hypothesis 4 (see Table 3, model 1), we found a significant positive effect $(\mathrm{p}<0.05)$ of the mediating variable (proactivity) on the independent variable (OSE in IS: time 2$)$. In the final step, in agreement with Hypothesis 5, it was found that gender had a significant negative indirect effect via proactivity on OSE in IS ( $a b=-0.20$, CI 95\% $[-0.14,-0.01])$.

\section{Discussion}

Students' OSE is important since on graduation crucial career decisions are made and effort and persistence are needed for the job search (Brown et al., 2006). Moreover, OECD surveys indicate that the link between the field of study at university level and the labour market is stronger for men than for women, since when women pursue STEM subjects they are less likely to end up working in a related field (OECD Council Report, 2012), making the question regarding the gender - IS students' OSE most relevant. Therefore, we tested the relationship of gender as well as of proactivity with the OSE of the IS students. First, in contrast to our expectation, gender had no effect on IS students' OSE beyond the effect of proactivity. However, as was expected, proactivity was positively related to the IS students' OSE beyond the effect of gender. Proactivity is a general dispositional tendency to feel a sense of agency across situations that spill over into specific domains, colouring an individual's self-efficacy judgments (Frese \& Fay, 2001). Proactive people tend to affect environmental change, feel relatively unconstrained by situational forces, and take upon themselves to have an impact on the situation they face rather than passively adapt to it (Bateman \& Crant, 1993; Crant \& Bateman, 2000). Therefore, proactivity is particularly important for self-efficacy in domains that are highly challenging, such as the IS prestigious and competitive occupational domain. This finding agrees with other studies that highlight the importance of proactivity not only for job success (e.g. Fuller \& Marler, 2009; Thomas et al., 2010), but also for special challenges such as a successful job search (Brown et al., 2006), and extraordinary leadership (Crant \& Bateman, 2000).

Furthermore, we also found that proactivity mediated an indirect negative effect of gender on IS students' OSE. The female IS students revealed a lower level of proactivity than the male students, and proactivity in its turn was highly predictive of their OSE, thus the female students achieved lower on their OSE compared to the male students. Therefore, gender inequality in IS students' OSE is originated by gender differences in the proactivity level.

The finding regarding the gender difference on the students' proactivity is intriguing. Beyond the importance of proactivity to IS students' OSE that was found here, proactivity was previously found as affecting desired work goals as job performance (Fuller \& Marler, 2009; Thomas et al., 2010), and leadership (Crant \& Bateman, 2000). Therefore, possible gender differences in proactivity are with theoretical and practical importance beyond the scope of OSE. However, to the best of our knowledge, no previous research has aimed at investigating gender differences in proactivity. Nevertheless, gender differences were previously found in such personality features as assertiveness and excitement seeking (Feingold, 1994; Costa et al., 2001), and proactivity was previously found as being positively related to the need for achievement and dominance (Bateman \& Crant, 1993). Also, gender self-concept is the distinction between more "masculine" traits that are agentic-instrumental traits (e.g. active, decisive), considered as more "masculine" in gender self-concept theory (Abele, 2003). Proactivity and proactive work behaviour are gaining increasing amounts of attention due to their importance in the dynamic and competitive work environment (e.g. 
Crant \& Bateman, 2000; Major et al., 2006; Seibert et al., 2001; Grant \& Ashford, 2008; Kim et al., 2009;Bindl, \& Parker, 2010; Li et al., 2010). Therefore, it is important to gain a more elaborate understanding regarding possible gender differences in proactivity among the general population, as well as in particular ages, cultures, or other groups. This line of research might be able to help in better understanding gender differences in work behaviour and achievements, as well as in other life domains.

In conclusion, we found that male and female IS students that had same level of proactivity were not different in their OSE. Nevertheless, on average the female students were less proactive than the male students, thus experienced lower OSE. This finding enhances priovious knowledege regarding the factors that contributes for the gender inequality in the transition from university to the labour market in STEM occupations (OECD Council Report, 2012).

\section{Research Limitations and Future Research}

The current research employed samples that included the students of an IS department in one academic institution in Israel. Therefore, more research is needed for assessing the present results' generalization. More specifically, first, this academic institution aims to advance the accessibility of academic education to the periphery, and it is located accordingly. Therefore, it might be that the IS occupational field is perceived by the students who participated in the study as more challenging than the general IS student population. Such a perception could further contribute to the intensity of the positive relation we found between proactivity and the students' OSE. Secondly, our sample refers to IS students, meaning that the females in our sample had already chosen a male-dominant field for their academic studies; therefore the gender difference in proactivity in the general population might be even stronger. Also, previous research has found a positive relation among the cultural dimension of masculinity versus its opposite, femininity and personality traits as openness to experience (Hofstede, 2004). Therefore, the gender differences we found in proactivity should be tested in different cultural settings as well (Costa et al, 2001). Thirdly, the sample is relatively homogenous regarding age, compared to the general adult population, including relatively young people.

Additionaly, we concentrated on IS students, but future research might test our results regarding the indirect effect of proactivity on OSE on other male-dominant occupations as well. Also, future research may test the strength of the proactivity-OSE link in more versus less challenging and competitive occupations.

We controlled for the age, socioeconomic level, academic achievements, and conscientiousness. However, larger samples are advised for future research for controlling more variables, such as differences in cultural background and geographic location or other possible personality traits, while preserving statistical power (Ellis, 2010).

\section{Practical Implications}

Since we found that proactivity affected the IS students' OSE, it is important to locate students with lower proactivity and expose them to relevant role models, and to supportive communication for increasing their OSE (Bandura, 2000).

Proactivity, unlike self-efficacy, is defined as a personality trait and therefore is less susceptible to change; more research is needed regarding its origin and development. However, there are some indirect encouraging findings regarding the possibility of nurturing it. For example, in a study with university graduates who were tested after graduation and 1.5 years later, it was found that agency influences career success and vice versa (Abele, 2003). Therefore, it is important to explore in future research the effect of role enactment and success on proactivity. This could have practical implications for the educator regarding the merit in encouraging girls and women in the education system's extra-curricular activities to such experiences.

\section{References}

Abele, A. E. (2003). The dynamics of masculine-agentic and feminine-communal traits: findings from a prospective study. Journal of Personality and Social Psychology, 85(4), 768-776. http://dx.doi.org/10.1037/0022-3514.85.4.768

Abele, A. E., \& Spurk, D. (2009). The longitudinal impact of self-efficacy and career goals on objective and subjective career success. Journal of Vocational Behavior, 74, 53-62. http://dx.doi.org/10.1016/j.jvb.2008.10.005

Bandura, A. (1986). Social foundations of thought and action: A social cognitive theory. Englewood Cliffs, NJ: Prentice Hall.

Bandura, A. (1997). Self-Efficacy: The Exercise of Control. New York: W. H. Freeman and Company.

Bandura, A. (2000). Self-efficacy. In A. E. Kazdin (Ed.), Encyclopedia of psychology. New York: Oxford University Press. 
Bandura, A. (2011). Social cognitive theory. In A. W. Kruglanski, E. T. Higgins, \& P. A. M. Van Lange (Eds.), Handbook of social psychological theories (pp. 349-373). London: SAGE.

Bateman, T. S., \& Crant, J. M. (1993). The proactive component of organizational behavior: A measure and correlates. Journal of Organizational Behavior, 14(2), 103-118. http://dx.doi.org/10.1002/job.4030140202

Betz, N. E., \& Hackett, G. (1981). The relationship of career-related self-efficacy expectations to perceived career options in college women and men. Journal of counseling psychology, 28(5), 399-410. http://dx.doi.org/10.1037/0022-0167.28.5.399

Bindl, U., \& Parker, S. K. (2010). Proactive work behavior: Forward-thinking and change-oriented action in organizations (Vol. 2, pp. 567-598). Washington, DC: American Psychological Association.

Brown, D. J., Cober, R. T., Kane, K., Levy, P. E., \& Shalhoop, J. (2006). Proactive personality and the successful job search: a field investigation with college graduates. Journal of Applied Psychology, 91(3), 717-726. http://dx.doi.org/10.1037/0021-9010.91.3.717

Bureau of Labor Statistics. (2004). The ten fastest growing occupations, 2002-12. Retrieved from http://www.bls.gov/news.release/ ecopro.t04.htm

Busch, T. (1995). Gender differences in self-efficacy and attitudes toward computers. Journal of Educational Computing Research, 12(2), 147-158. http://dx.doi.org/10.2190/H7E1-XMM7-GU9B-3HWR

Clark Blickenstaff, J. (2005). Women and science careers: leaky pipeline or gender filter? Gender and Education, 17(4), 369-386. http://dx.doi.org/10.1080/09540250500145072

Correll, S. J. (2001). Gender and the career choice process: The role of biased self-assessments. American Journal of Sociology, 106(6), 1691-1730.

Correll, S. J. (2004). Constraints into preferences: Gender, status, and emerging career aspirations. American Sociological Review, 69(1), 93-113. http://dx.doi.org/10.1177/000312240406900106

Costa Jr, P., Terracciano, A., \& McCrae, R. R. (2001). Gender differences in personality traits across cultures: robust and surprising findings. Journal of Personality and Social Psychology, 81(2), 322-331.

Crant, J. M., \& Bateman, T. S. (2000). Charismatic leadership viewed from above: The impact of proactive $\begin{array}{lllll}\text { personality. } & \text { Journal of }\end{array}$ http://dx.doi.org/10.1002/(SICI)1099-1379(200002)21:1<63::AID-JOB8>3.0.CO;2-J

Ellis, P. D. (2010). The essential guide to effect sizes: Statistical power, meta-analysis, and the interpretation of research results. Cambridge, England: Cambridge University Press. http://dx.doi.org/10.1017/CBO9780511761676

Feingold, A. (1994). Gender differences in personality: a meta-analysis. Psychological Bulletin, 116(3), 429-456. http://dx.doi.org/10.1037/0033-2909.116.3.429.

Frese, M., \& Fay, D. (2001). Personal initiative: An active performance concept for work in the 21st century. Research in Organizational Behavior, 23, 133-187. http://dx.doi.org/10.1016/S0191-3085(01)23005-6

Fuller Jr, B., \& Marler, L. E. (2009). Change driven by nature: A meta-analytic review of the proactive personality literature. Journal of Vocational Behavior, 75(3), 329-345. http://dx.doi.org/10.1016/j.jvb.2009.05.008

Grant, A. M., \& Ashford, S. J. (2008). The dynamics of proactivity at work. Research in Organizational Behavior, 28, 3-34. http://dx.doi.org/10.1016/j.riob.2008.04.002

Hackett, G., \& Betz, N. E. (1981). A self-efficacy approach to the career development of women. Journal of vocational behavior, 18(3), 326-339. http://dx.doi.org/10.1016/0001-8791(81)90019-1

Hofstede, G., \& McCrae, R. R. (2004). Personality and culture revisited: Linking traits and dimensions of culture. Cross-cultural Research, 38(1), 52-88. http://dx.doi.org/10.1177/1069397103259443

Hurtz, G. M., \& Donovan, J. J. (2000). Personality and job performance: the Big Five revisited. Journal of Applied Psychology, 85(6), 869-879. http://dx.doi.org/10.1037//0021-9010.85.6.869

John, O. P., \& Srivastava, S. (1999). The Big-Five trait taxonomy: History, measurement, and theoretical perspectives. In L. A. Pervin \& O. P. John (Eds.), Handbook of personality: Theory and research (Vol. 2, pp. 102-138). New York: Guilford Press.

Kim, T. Y., Hon, A. H., \& Crant, J. M. (2009). Proactive personality, employee creativity, and newcomer outcomes: A longitudinal study. Journal of Business and Psychology, 24(1), 93-103. http://dx.doi.org/10.1007/s10869-009-9094-4 
Li, M., Liu, Y., Liu, L., \& Wang, Z. (2016). Proactive personality and innovative work behavior: the mediating effects of affective states and creative self-efficacy in teachers. Current Psychology, 1-10. http://dx.doi.org/10.1007/s12144-016-9457-8

Li, N., Liang, J., \& Crant, J. M. (2010). The role of proactive personality in job satisfaction and organizational citizenship behavior: a relational perspective. Journal of Applied Psychology, 95(2), 395-404. http://dx.doi.org/10.1037/a0018079

Lishan, X., Xinhua, G., \& Peifang, Z. (2013). Impact of learning orientation and proactive personality on employee creativity in exhibition: mediation effect of creative self-efficacy. China Management Studies, 3, 005.

Luzzo, D. A., \& Taylor, M. (1994). Effects of verbal persuasion on the career self-efficacy of college freshmen. California Journal of Counseling and Development Journal, 14, 31-34.

Major, D. A., Turn-er, J. E., \& Fletcher, T. D. (2006). Linking proactive personality and the Big Five to motivation to learn and development activity. Journal of Applied Psychology, 91(4), 927-935. http://dx.doi.org/10.1037/0021-9010.91.4.927

Ncwit (National Center for Women and Information Technology). (2010). Women in IT: The Facts. Retrieved April 2012, from http://www.ncwit.org/resources.thefacts.html

Nielsen, S., \& Von Hellens, L. (2006). The Social Construction of Australian Women in IT.Encyclopedia of Gender and Information Technology. E. Trauth. Hershey, Idea Group: 1105-1111.

OECD Council Report. (2012), Gender Equality in Education, Employment and Entrepreneurship. Paris: Final Report to the MCM 2012 Meeting of the OECD Council at Ministerial Level.

Pajares, F. (1996). Self-efficacy beliefs in academic settings. Review of Educational Research, 66(4), 543-578. http://dx.doi.org/10.3102/00346543066004543

Parker, S.K. (1998). Enhancing role breadth self-efficacy: The roles of job enrichment and other organizational interventions. Journal of Applied Psychology, 83, 835-852. http://dx.doi.org/10.1037//0021-9010.83.6.835

Podsakoff, P. M., MacKenzie, S. B., Lee, J. Y., \& Podsakoff, N. P. (2003). Common method biases in behavioral research: a critical review of the literature and recommended remedies. Journal of applied psychology, 88(5), 879. http://dx.doi.org/10.1037/0021-9010.88.5.879

Rigotti, T., Schyns, B., \& Mohr, G. (2008). A short version of the occupational self- efficacy scale: Structural and construct validity across five countries. Journal of Career Assessment, 16(2), 238-255. http://dx.doi.org/10.1177/1069072707305763

Schwarzer, R., \& Fuchs, R. (1995). Changing risk behaviors and adopting health behaviors: The role of self-efficacy beliefs. In: A. Bandura (Ed.), Self-efficacy in Changing Societies (pp. 259-288). Cambridge University Press.

Schyns, B., \& von Collani, G. (2002). A new Occupational Self-Efficacy Scale and its relation to personality constructs and organizational variables. European Journal of Work and Organizational Psychology, 11, 219-241. http://dx.doi.org/10.1080/13594320244000148

Seibert, S. E., Crant, J. M., \& Kraimer, M. L. (1999). Proactive personality and career success. Journal of Applied Psychology, 84(3), 416-427. http://dx.doi.org/10.1037/0021-9010.84.3.416

Seibert, S. E., Kraimer, M. L., \& Crant, J. M. (2001). What do proactive people do? A longitudinal model linking proactive personality and career success. Personnel Psychology, 54(4), 845-874. http://dx.doi.org/10.1111/j.1744-6570.2001.tb00234.x

Shelton, S. H. (1990). Developing the construct of general self-efficacy. Psychological Reports, 66, 987-994.

Spurk, D., \& Abele, A. E. (2014). Synchronous and time-lagged effects between occupational self-efficacy and objective and subjective career success: Findings from a four-wave and 9-year longitudinal study. Journal of Vocational Behavior, 84(2), 119-132. http://dx.doi.org/10.1016/j.jvb.2013.12.002

Thomas, J. P., Whitman, D. S., \& Viswesvaran, C. (2010). Employee proactivity in organizations: A comparative meta - analysis of emergent proactive constructs. Journal of Occupational and Organizational Psychology, 83(2), 275-300. http://dx.doi.org/10.1348/096317910X502359

Xie, J., Chu, X., Zhang, J., \& Huang, J. (2014). Proactive personality and voice behavior: The influence of voice self-efficacy and delegation. Social Behavior and Personality: An International Journal, 42(7), 1191-1200. http://dx.doi.org/10.2224/sbp.2014.42.7.1191 